\title{
LABORATORY EXPERIMENTS ON HYGROTHERMAL BEHAVIOUR OF REAL-SCALE TIMBER WALLS
}

\author{
Helisoa Rafidiarison ${ }^{1,2}$, Eric Mougel ${ }^{1 \oplus}$, Alexis Nicolas ${ }^{3}$
}

\begin{abstract}
Hygrothermal performance of massive wood and wooden materials used as structural purposes in building envelope are measured by means of laboratory tests. For this purpose, hygrothermal short-time behaviour of two massive timber walls exposed to summer climatic conditions were investigated. A double climatic chamber simulating real on-site conditions was designed and built at the LERMAB/ENSTIB site in Epinal and used during wall behaviour assessment. Temperature and humidity variations with time were measured at different locations to determine profiles evolution of the investigated wall layers. Our results showed a contribution of wood and wooden insulation products in improving indoor thermal climate, as these materials allow a decrease and a significant delay of the important temperature variation of outdoor climate. Laboratory result was also compared to field measurement for the cross-laminated wall system, time lag values for north and south walls showed that solar radiation have a non negligible effect on temperature propagation within the wall. The variation of absolute humidity of the air in the cavity around humidity sensors installed in wall layers shows significant dependence with temperature variation. This phenomenon is consistent with the storage or realising of humidity during hygroscopic equilibrium between wood-based materials and its surrounding air.
\end{abstract}

Keywords: Timber walls, hygrothermal behaviour, climatic chamber, thermal comfort, experiments, hygroscopic material.

\section{INTRODUCTION}

These last years, increased interest was given to wood and wood-based products used as structural materials in building envelopes. This increased attention of using wooden materials is due to an increased public awareness of environmental issues. Indeed, building industry has to consider more and more energy efficiency and indoor comfort in building conception. The good contribution of wooden materials in building envelope energetic performance and indoor comfort increases the interest given to this material. In this paper, the study is focused on better understanding of wood contribution to improve indoor comfort.

Wood as a hygroscopic material has the capacity to store or release moisture to the surroundings according to the relative humidity of the ambient air. This property of wood and wooden materials has been largely investigated in many research works which showed wooden material ability to damp indoor humidity fluctuations and assure indoor hygric comfort, (Hameury 2005, Kunzel et al. 2004, Osanyintola et al. 2006, Osanyintola and Simonson 2006, Simonson et al. 2004, James et al. 2010, Talukdar et al. 2007). Most of the experimental and numeric research works aimed at assessing wood material performance are focused on the heat and moisture transfer in timber frame systems.

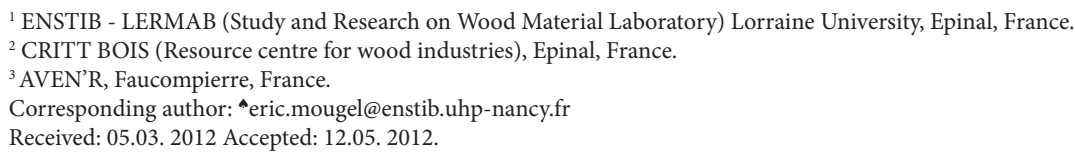


Furthermore, timber walls are also interested since wooden materials contribute to improve indoor thermal comfort. Thermal diffusivity of wood, which describes how fast temperature fluctuations propagate in materials and wall, is low enough to allow a delay of temperature variations from outdoor to indoor climate. Wood contributes also to moderate temperature amplitudes during summer period. Both properties are known as time lag and decrement factor respectively. For wood, these thermal properties have been investigated only for each material but not in the case of a multilayer wall, as used in building envelope structure (Asan 1998, Asan 2006). To assess time lag and decrement factor of a given wall, a simplified calculation method is used to determine the thermal diffusivity which depends mainly on the thermal conductivity and specific heat capacity of the wall. In a porous material like wood, speed of heat propagation within the material depends not only on heat transfer by conduction but also on convection. As thermal conductivity considers only the internal convection in material pores, the heat transferring with the air flow through the wall assembly is then not taken into account in thermal diffusivity calculation. Error may occur when determining time lag and decrement factor of some wooden assemblies within which convection is not negligible. Further studies are then required to improve knowledge of thermal unsteady state behaviour of timber construction, especially envelope made with porous and lightweight wooden materials which are more subjected to heat transfer by convection. Previous study has shown the importance of the effect of moisture transport on heat load through porous walls (Mendes et al. 2003). It has been shown that models that ignore moisture transfer may overestimate conduction peak loads (Mendes et al. 2003) and underestimate heat flux through the structures. Then, to determine accurately the time lag and decrement factor provided by heavy timber structure, it is important to achieve laboratory and field studies on real hygrothermal behaviour of wooden structures under summer conditions.

The reported work deals with short-time investigation of moisture and thermal behaviour of two massive timber wall systems: the first one consists of piled beams with wooden internal insulation whereas the second is made of cross-laminated timber with external wood fibre insulation. The aim of the study reported in this paper is to determine the time lag and decrement factors of both tested walls and their components and assess the hygrothermal behaviour of the assemblies directly exposed to outdoor summer conditions. Short-time behaviour of the tested walls exposed to summer unsteady state conditions was studied by means of laboratory measurements. The first part of this paper reports the double climatic chamber characteristics. This apparatus was designed and built on the LERMAB (Study and Research on Wood Material Laboratory) site in Epinal, France to investigate the hygrothermal behaviour of full scale walls exposed to various indoor and outdoor climatic conditions. The second part deals with the experimental procedure used for investigating short-time behaviour of the tested wall. The last part presents the main results obtained during the research work. The main objective of this paper is to obtain reliable information helping to better understand the contribution of massive wood wall and wooden materials on indoor comfort and thermal performance.

\section{MATERIAL AND METHODS}

\section{Experimental facility}

A double climatic chamber (Figure 1) was designed and built to achieve steady-state and transient laboratory experiments on hygrothermal behaviour of full-scale walls. The design of the climatic chamber was based in part on the ISO 8990 standard for measuring thermal transmission properties using the calibrated and guarded hot box method. The experimental facility allows measuring transient temperature and moisture distribution within the massive timber wall assemblies tested. 
The apparatus consists of two separated climatic chambers, between which the tested wall is installed for steady-state or dynamic tests. In the two climatic chambers, called exterior chamber and interior chamber, cooling, heating and also humidification units are installed to simulate exterior and interior temperature and humidity climatic conditions, respectively. Other parameters can also be controlled in each chamber during the tests e.g. differential pressure and air flow velocity. The walls of the chambers consist of $120 \mathrm{~mm}$ of polyurethane insulation with aluminium foils in the exterior and interior sides. The total cross section of each chamber is $2.8 \mathrm{~m} \mathrm{x} 3 \mathrm{~m}$ with a height of $2.8 \mathrm{~m}$. Thus, the facility allows testing of a wall with a dimension of $2.8 \mathrm{~m}$ wide and $2.8 \mathrm{~m}$ high, measurements area is located in the centre of the wall so that edge effect can be avoided.

In the interior chamber, an electric resistance of $2500 \mathrm{~W}$ is used as a heat source, the interior air is cooled with a refrigerating unit and humid air can be produced with a vaporizing system including an electric resistance of $250 \mathrm{~W}$. These installed systems allow maintaining temperature and humidity in the chamber in respective ranges of $[0 ;+30]{ }^{\circ} \mathrm{C}$ and $[30 ; 95] \%$.

For the exterior chamber, the heating system consists of an electric resistance of $4000 \mathrm{~W}$ and the cooling system is also a refrigerating unit which allows controlling negative temperature in the chamber. The system includes the same humidification system as the interior chamber. With this arrangement, exterior climatic conditions between -15 and $45^{\circ} \mathrm{C}$ for temperature and 30 and $95 \%$ for relative humidity can be simulated in the chamber.

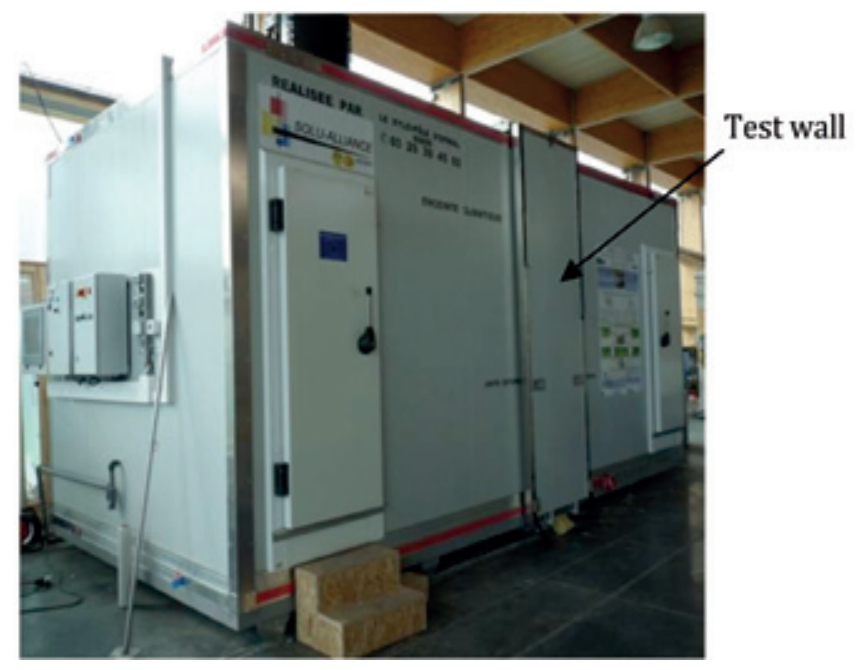

Figure 1. The double climatic chamber.

For tests where measurements of heat and moisture flows across the tested wall are performed, such as thermal transmission properties measurement according to ISO 8990 (1996), a metering chamber with dimensions of $1.4 \mathrm{~m}$ wide by $0.65 \mathrm{~m}$ thick by $1.4 \mathrm{~m}$ high is used (Figure 2 ). This metering chamber is located in the interior chamber. Its walls consist of $60 \mathrm{~mm}$ of polyurethane insulation. An electric resistance of $55 \mathrm{~W}$ is used to control the metering chamber temperature during test and a saturated salt solution controls the humidity of the chamber. The use of the metering chamber in heat flow measurement allows minimizing the heat loss through the walls of the chamber. 


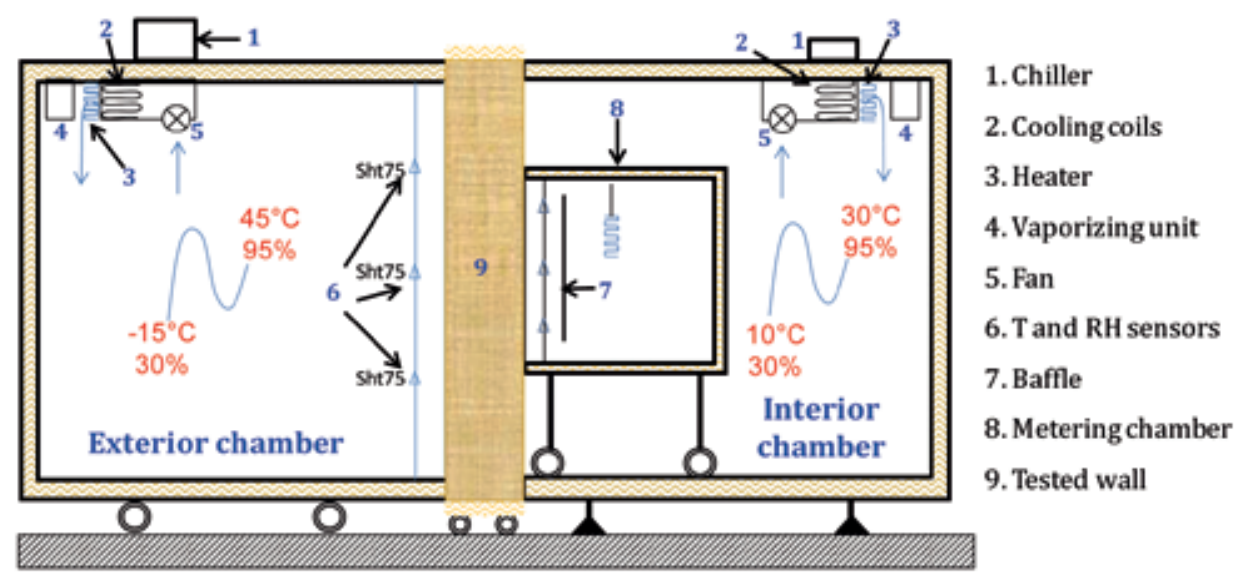

Figure 2. Schematic diagram of the experimental facility.

\section{Measuring technology}

During measurement, temperature and relative humidity changes are measured in different parts of the experimental facility: inside the exterior and interior chambers, at the interior and exterior surfaces of the tested wall and at different locations inside the tested wall.

In order to verify the homogeneity of air flow in interior and exterior chambers, air temperatures and relative humidity distribution in the two chambers of the apparatus are measured using SHT75 sensors from Sensirion Company. In each chamber, nine sensors are arranged and installed at a distance of $150 \mathrm{~mm}$ from the wall surface, as shown in figure 3 .

Interior and exterior surface temperatures of the tested wall are measured using nine T-type thermocouples (copper and constantan) with $0.25 \mathrm{~mm}$ diameter wires. SHT 75 sensors are also installed on each wall surface to determine air relative humidity close to the surface. Humidity sensors are at the same location as thermocouples.

To assess the hygrothermal short-time behaviour of the tested wall, temperature and relative humidity profiles are measured within the wall by means of SHT 75 capacitive sensors from Sensirion Company. The sensors measure temperature and relative humidity of the air around the material, which allows deducing the air absolute humidity. As material and the surrounding air around are assumed to be in moisture equilibrium, it is possible to deduce instantaneous moisture content of the different material layers.

SHT75 sensor uses a capacitive sensor element for measuring relative humidity and a band-gap sensor for temperature measurement. It has the advantage of having long term stability and being fully calibrated so that no additional calibration is needed for the use of the sensor. The SHT75 sensors can be used in the humidity range of 0 - $100 \%$ with an accuracy of $\pm 1.8 \%$. The operating temperature range of the sensor is $-40 ;+123.8^{\circ} \mathrm{C}$. In our temperature test range, the accuracy of SHT75 sensors is about $\pm 0.5^{\circ} \mathrm{C}$. 


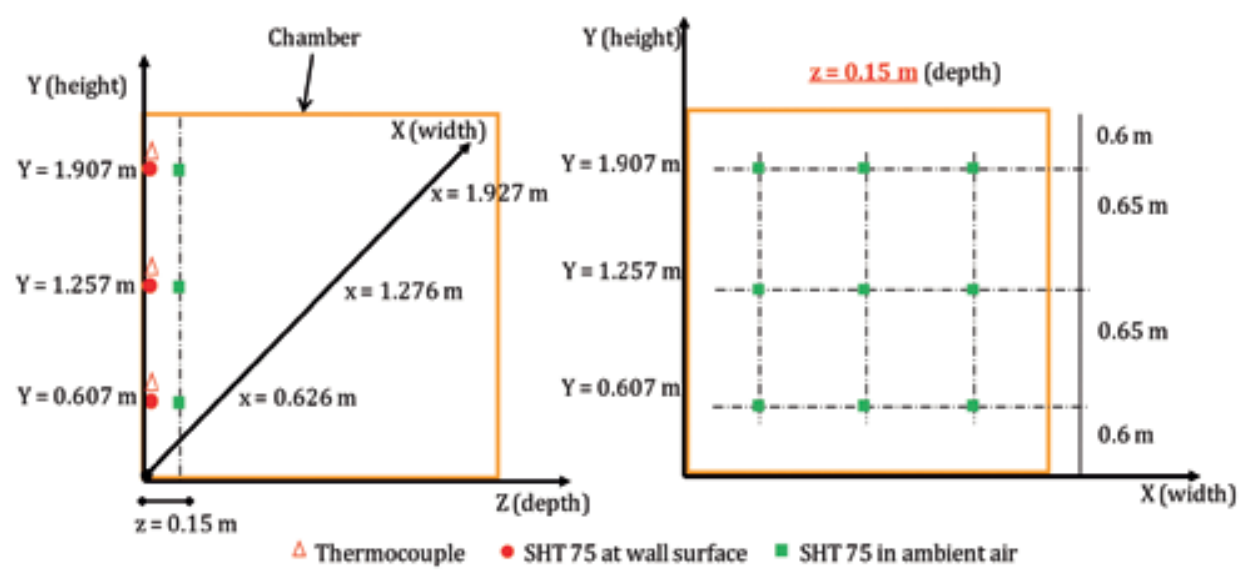

Figure 3. Sensors arrangement inside the chambers (a) side view (b) front view.

A data acquisition and control system is used for parameter logging during tests with registration every 15 minutes. The data acquisition system is operated by a computer and includes:

- 32 temperature measurement channels,

- 124 temperature and humidity measurement channels (for SHT 75 sensors)

- 64 voltage input channels

- 12 electric energy counter channels

- 8 I/O relay channels.

\section{Description and preparation of the wall assembly}

Wall systems used for hygrothermal short-time experiment was chosen to match the typical massive timber construction. Measurements were performed first on a massive timber wall assembly (wall A) made of piled beam with internal natural insulation made from hemp and wood fibres. The wall was built between the two chambers panelling. The second test wall is made of cross-laminated timber structure (wall B). The compositions of the tested walls are given in the following figures.

The massive timber assembly was built directly between the two environmental chambers to allow easy installation of temperature and humidity probes at different locations within the wall layers, as shown in figure 4 (mainly at materials interfaces). For monitoring material moisture content, small SHT 75 sensors were installed in drilled holes which were filled up with wood pieces and then closed by silicon to ensure a sealed environment around the sensors. 


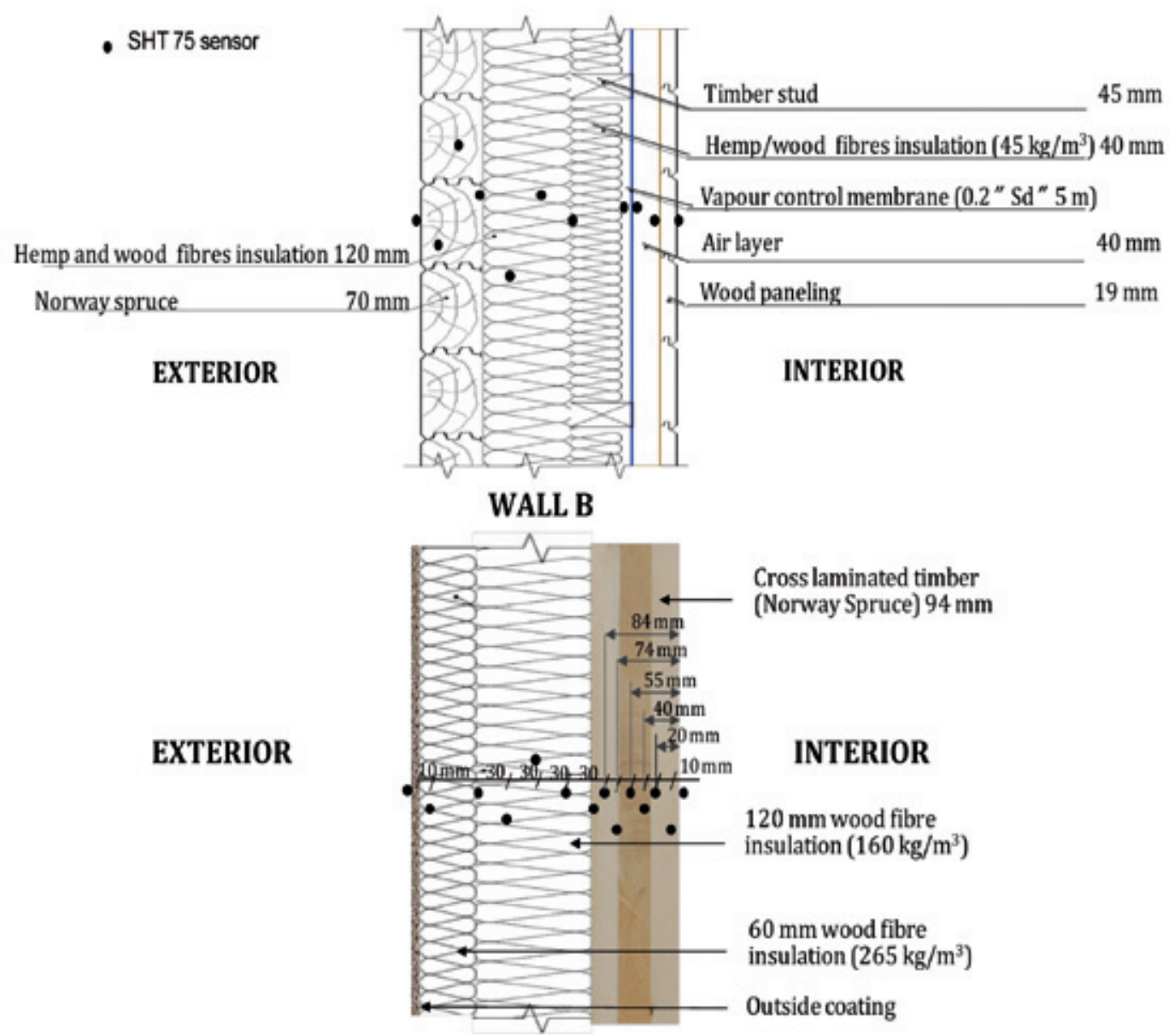

Figure 4. Cross-section and location of the sensors inside the tested walls.

After wall building and installation of the sensors, the two chambers between which the tested wall was installed were connected. To avoid lateral flows and achieve one-dimensional heat and moisture transport in the investigated wall, lateral faces of the timber wall was sealed with a vapour barrier and insulated with a combination of $100 \mathrm{~mm}$ mineral wool insulation and $60 \mathrm{~mm}$ polyurethane boards.

\section{Test conditions}

The experiment was preceded by a 2-days pre-conditioning phase in order to achieve a uniform initial temperature within each wall. For this purpose, indoor and outdoor conditions were set to $20^{\circ} \mathrm{C} 40 \%$ relative humidity. Two means of monitoring moisture content in materials were employed to determine wood initial moisture content: the first method uses resistive probes which are used for wood moisture content measurement. The second method, called gravimetric method, consists of sampling wood pieces which are weighed and oven-dried at $103^{\circ} \mathrm{C}$ until the weight is stable. The samples are then re-weighed and the difference between initial and final weight of each sample gives its initial moisture content.

After pre-conditioning phase, dynamic test was performed during 7 days by exposing the wall exterior face to transient summer conditions. The real climatic data for temperature and relative humidity corresponding to 7 days of a hot summer period measured in Vosges area - France in 2010 
were simulated in the exterior chamber. These climatic data were chosen to assess the real massive timber wall behaviour during hot period and the impact on indoor climate. In the indoor chamber simulating indoor conditions, constant temperature and relative humidity of $20^{\circ} \mathrm{C} 40 \%$ were set up.

\section{RESULTS AND DISCUSSION}

Time lag and decrement factor are very important characteristics used for assessing good thermal comfort contribution of any material. Time lag corresponds to the time it takes for outdoor temperature oscillations to propagate from the outer surface to the inner surface of a wall. The decreasing ratio of the temperature amplitude between the inner surface and the outer surface of the wall is named decrement factor (Asan 1998). More information about these two parameters is given in the work of Asan (2006). To obtain a good indoor comfort, with an almost constant temperature, building walls need to have high time lags (in hours) and low decrement factors.

Figure 5 shows consecutive monitoring days of the thermal behaviour of the piled beam wall during test with outdoor summer period. The variation of inside temperature is due to regulation. As the figure of 2-days results facilitates the view of the time lag provided by each material whereas in a figure of 7-days results (duration of the experiment) the time lag value would be difficult to observe, we chose to show the results only for two consecutive monitoring days. Results on figure 5 have shown that each wall material layer contributes to a delay of the outside temperature oscillation amplitudes on inside temperature.

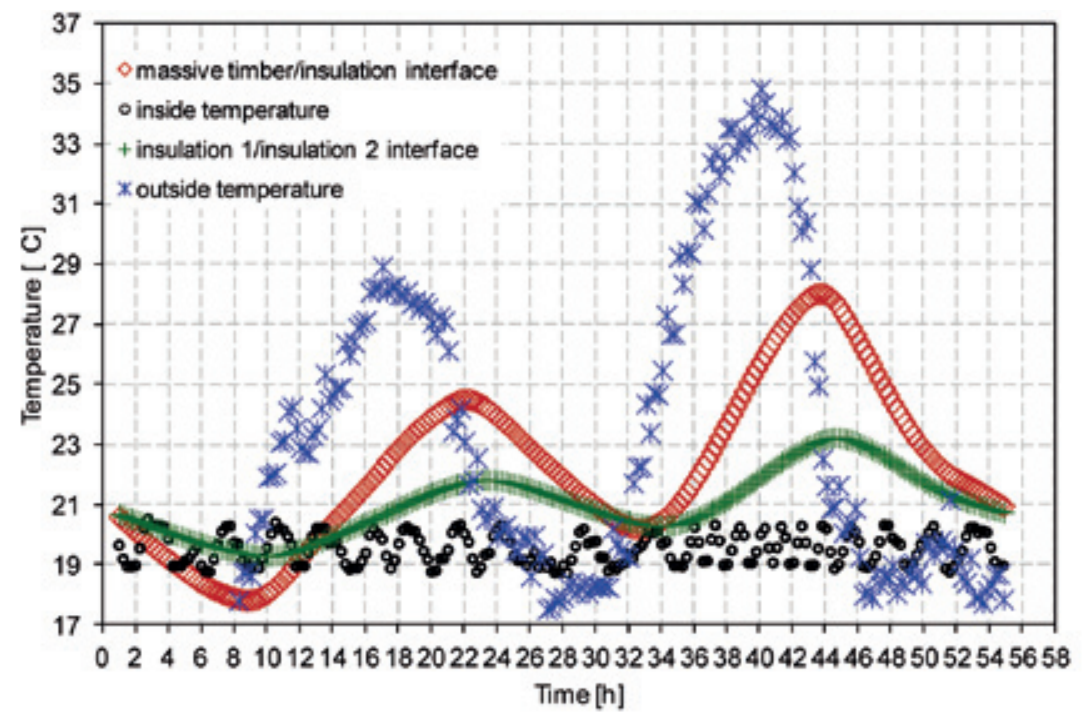

Figure 5. Piled beams wall temperature variation during 2-days summer period.

The $70 \mathrm{~mm}$ massive timber material (piled beams of the wall A) close to the outdoor environment provides an average time lag of 4 hours of the outside temperature peaks. The calculated value obtained by Asan (1998) in his work shows a 14 hours for $200 \mathrm{~mm}$ thick wood wall. Another study (Asan 2006) aimed at investigating time lags and decrement factors for different materials gives a 2.27 $\mathrm{h}$ and $5.89 \mathrm{~h}$ for $5 \mathrm{~cm}$ and $100 \mathrm{~mm}$ thick wood board respectively. These results are consistent with the present experimental result in which a $4 \mathrm{~h}$ time lag is obtained for $70 \mathrm{~mm}$ thick massive wood. The same $70 \mathrm{~mm}$ massive wood shows another interesting behaviour: results on Figure 5 show that the massive wood material provides a significant attenuation of the outside temperature amplitudes, then an interesting decrement factor, because the temperature amplitude at massive timber/insulation 
interface is largely lower than the amplitude of outside temperature. These behaviours show that wood contributes to indoor thermal comfort improvement during summer period.

A simple analysis of the temperature variation in the wall A layers (Figure 5) showed that the $120 \mathrm{~mm}$ thick of hemp and wood insulation, close to the indoor environment, provides only one hour and a half time lag. This experimental result is not consistent with value given by time lag calculation (Eq. 1), which is largely higher (4.25 hours). As explained above, simple calculation of thermal diffusivity is only based on heat conduction and internal convection within materials pores, and neglects the effect of heat transport by the air flow on the heat transfer time across the material. Additional tests would be necessary to get more information on the conduction and convection contribution on time lag provided by low density fibre insulation. Despite of the non significant fibre insulation time lag, the $50 \%$ low decrement factor provided by this material contribute to improve indoor thermal comfort, with the whole wall decrement factor, indoor temperature remains almost constant over time.

Figure 6 shows the variation of temperature profile inside the materials layers of the crosslaminated timber wall. The result shows that the mean time lag of temperature oscillation provided by the $160 \mathrm{~kg} / \mathrm{m}^{3}$ density wood fibre insulation $(60 \mathrm{~mm})$ is about 1.75 hours whereas thermal diffusivity calculation (Eq. 1) predicts a time lag of four hours. The $60 \mathrm{~mm}$ thick wood fibre insulation (density $=265 \mathrm{~kg} / \mathrm{m}^{3}$ ) corresponds to a measured value of time lag of three hours when the calculated value is about 4.7 hours. It can be seen that these heavier wooden insulation have a greatest capacity to moderate temperature propagation within the wall than the lightweight insulation even if they have a lower thickness: the heavier material providing the higher time lag. We also observe that difference between calculated and measured values of time lag for wooden insulation materials is greater for light materials. As air flow transport is less important in heavier material, the effect of heat transport by convection on total heat transfer kinetic is then less important so that the error occurred when calculating this parameter without taking into account the heat transport by convection is lower.

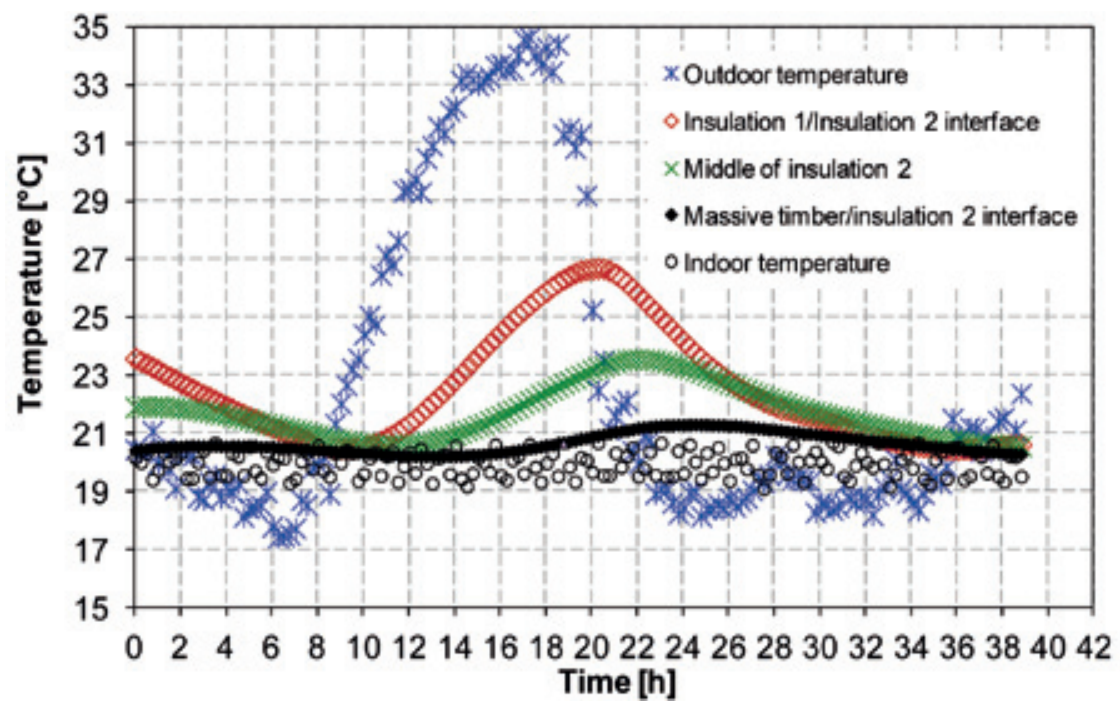

Figure 6. Cross-laminated timber wall temperature variation during a summer day.

The time lag calculation considered in this paper is time lag that we calculated based on the simple relation below using thermal diffusivity and used by insulation manufacturer: 


$$
\theta=\frac{24 . e \cdot \sqrt{\rho \cdot \Pi \cdot C_{p}}}{2 \Pi \sqrt{24 \lambda .3600}}
$$

Where:

The thermal diffusivity is given by the relation: $a=\frac{\lambda}{\rho \cdot C_{p}}$

$\theta \quad$ : is the time lags (hours)

e : material thickness $(\mathrm{m})$

$\rho \quad$ : The density of material $\left(\mathrm{kg} / \mathrm{m}^{3}\right)$

$\mathrm{C}_{\mathrm{p}}$ : the specific heat capacity of the material (J/kg.K)

One must consider that laboratory investigation of full scale wall only uses temperature and humidity climate conditions and does not include other parameters like wind speed and direction, air pressure, precipitation and solar radiation. Previous studies have shown that solar absorptivity of south wall has an effect on lime lag, decrement factor and temperature variations within the wall (Kontoleon and Bikas 2007). To determine the difference on time lag measured values between laboratory investigation and real-site behaviour of massive timber wall structures, we compared laboratory measurements of the cross-laminated timber wall with its behaviour when exposed to real-site conditions during field campaign measurement in Epinal. For the field campaign, we consider a test-room ( $3 \mathrm{~m}$ wide ${ }^{\star} 3 \mathrm{~m}$ length ${ }^{\star} 2.4 \mathrm{~m}$ height) with adiabatic ceiling and floor and walls made with the same cross-laminated timber wall composition.

Figure 7 and figure 8 give the temperature profiles within north and south walls respectively. According to temperature variations, the north wall seems to present the same mean time lag that the measured value in laboratory climatic chambers. This can be due the fact that solar radiation is lower at north than other orientations. On figure 5 time lag has significantly decreased compared to laboratory measurement. Kontoleon and Bikas (2007) and have shown that this difference depends on material solar absorptivity: time lag value increase when solar absorptivity increases up to 0.2 and decreases for solar absorptivity further increase.

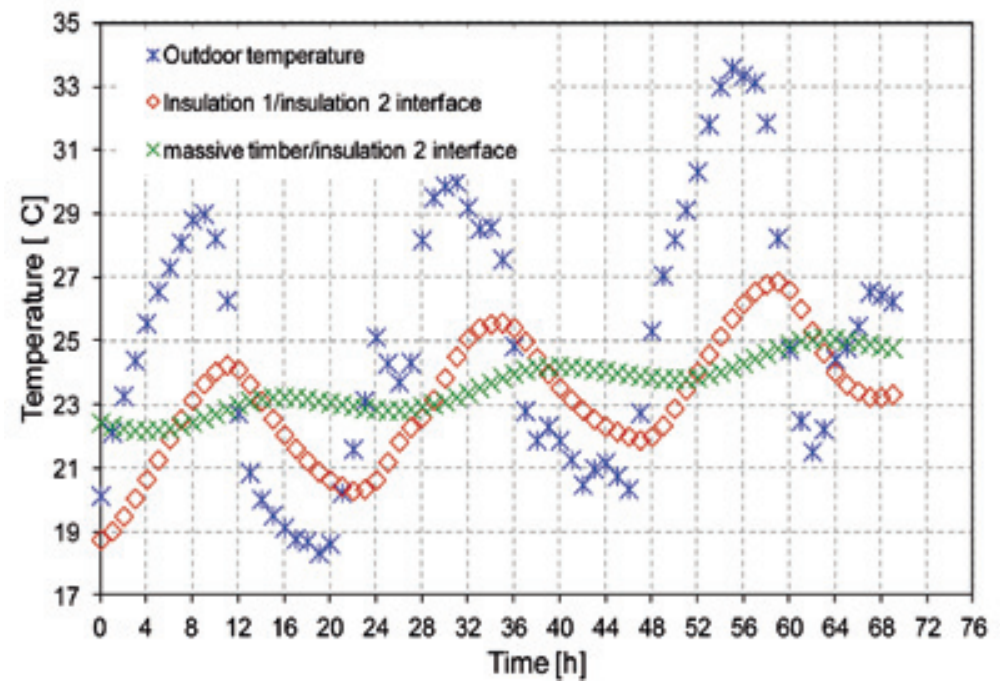

Figure 7. Temperature variation of the north cross-laminated timber wall in summer period during field measurement 


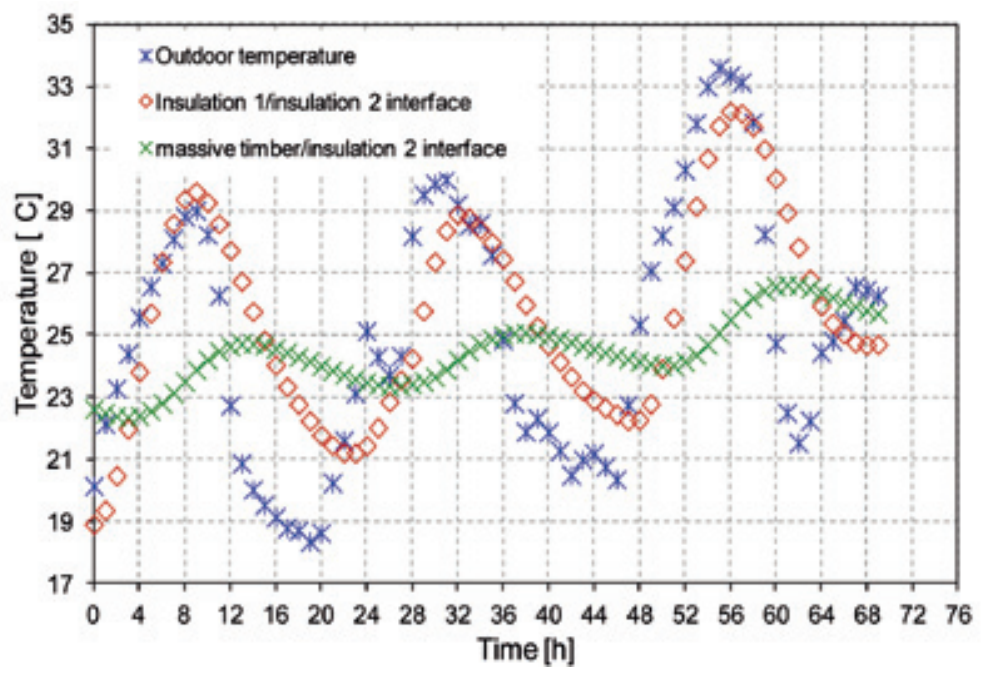

Figure 8. Temperature variation of the south cross-laminated timber wall in summer period during field measurement.

Experimental results of the hygrothermal performance of the external massive wood and the insulation made from hemp and wood fibres have shown that relative humidity in these materials follows the temperature evolution within time. Figure 9 and figure 10 show both air relative humidity measured with sensors and the air relative humidity calculated without hygroscopic effect on air moisture evolution. Figure 9 and figure 10 show that an increase of temperature in the materials involves an increase of air relative humidity around the sensors, the same behaviour occurs for a decrease of temperature. This behaviour could be attributed to the hygroscopic property of both lignocellulose-based materials. Actually, when temperature is increasing, wood material releases moisture into its surrounding air in the hole in which humidity sensor is installed, it leads to an increase of the air absolute humidity. This behaviour is consistent with the storage or realising of humidity during hygroscopic equilibrium between wood-based material and its surrounding air.

The present work concerns only the moisture buffering capacity of lignocelluloses-based materials within the construction. Another experiment will be performed later to investigate the effect of the moisture buffering capacity of these materials on indoor humidity. This future work will also assess the influence of mass transfer across the wall on its thermal behaviour by comparing the behaviour of lignocellulose-based materials with that of non hygroscopic products having similar thermal conductivity and density. 


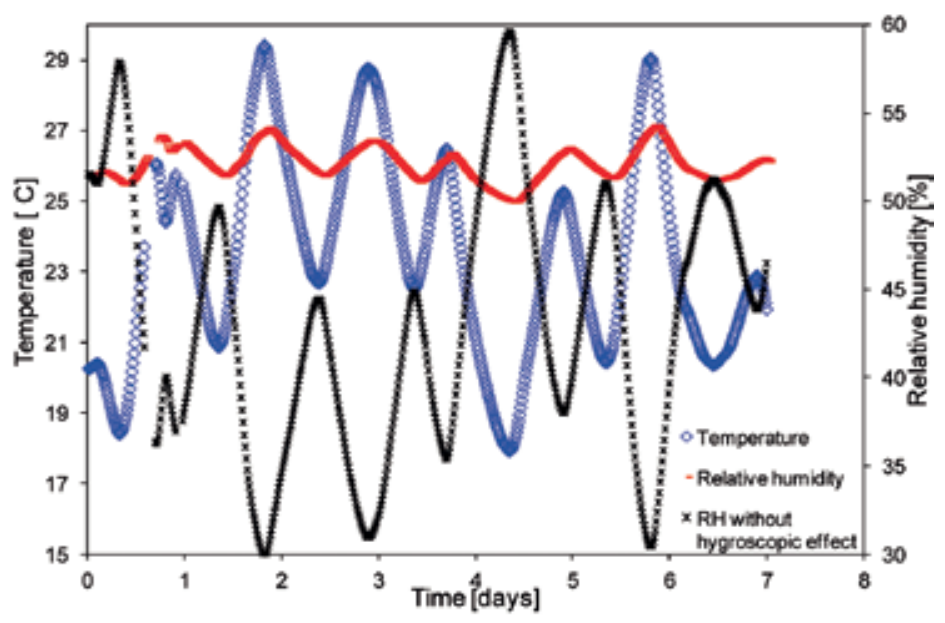

Figure 9. Relative humidity and temperature measured at depth of $60 \mathrm{~mm}$ in the massive wood (from outer surface) and relative humidity calculated without hygroscopic effect.

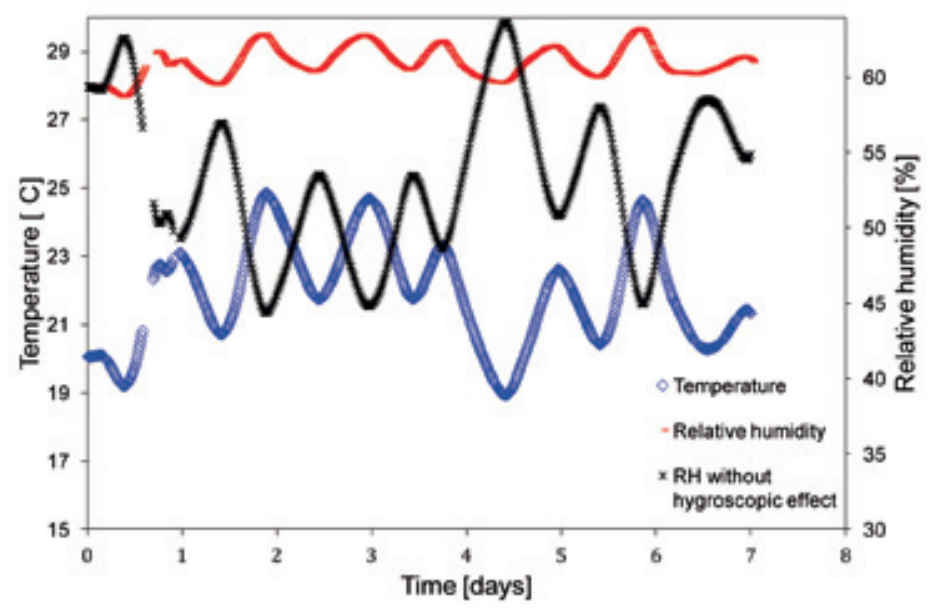

Figure 10. Relative humidity and temperature measured in the natural fibre insulation, at depth of $90 \mathrm{~mm}$ from massive timber/insulation interface and relative humidity calculated without hygroscopic effect.

\section{CONCLUSIONS}

The thermal and moisture behaviour of two massive timber walls exposed to short-time outdoor summer climatic conditions was studied using a double climatic chamber simulating on-site conditions. The measured results showed good thermal performance of the massive wood in delaying of 4 hours the temperature peaks from outdoor to indoor during summer period, an attenuation of outside temperature amplitude provided by the wood layer was also observed. The results also revealed a low time lag of an hour and a half for the $120 \mathrm{~mm}$ thick thermal insulation material made of hemp and wood fibres. However, this fibrous material provides a very low decrement factor which leads to an almost constant indoor temperature. Results obtained in this study have shown that the heavier wooden material provides the highest time lag value. We also observe that difference 
between calculated and measured values of time lag for wooden insulation materials is greater for light materials. This property can be related to the effect of heat transport with air flow within the materials.

Our results showed the contribution of massive wood and wood-based insulation in improving indoor thermal climate as outdoor temperature amplitude is more and more attenuated and temperature peak more and more delayed from the outside to the inside environment.

We compared time lag values obtained with laboratory experiments to those of field measurement for the cross-laminated wall system. Results showed that time lag values obtained during laboratory experiments and those measured on the south wall are completely different due to the effect of solar radiation on temperature propagation within the south wall. To accurately determine time lag of the heat wave propagation within a wall, the influence of solar radiation on walls of different orientations is an important parameter that must be considered.

As moisture is a parameter which has an effect on thermal transfer, hygroscopic behaviour of massive wood and fibre insulation was also observed with moisture content monitoring with the capacitive sensors installed in drilled holes inside the wall. When temperature increases, wood material releases moisture into the surrounding air in drilled holes which increases air absolute humidity. An increase of temperature is then accompanied by an increase of air relative humidity. The opposite phenomenon occurs when temperature decreases. This behaviour is consistent with the storage or realising of humidity during hygroscopic equilibrium between wood-based material and air. Additional experiments aimed at determining the same behaviour for a longer period are currently performed with the same wall system in order to assess the importance of this behaviour on heat and moisture transport across the wall, indoor comfort and thermal performance of construction.

\section{ACKNOWLEDGEMENTS}

The construction of the double climatic chambers was funded by the "European Fund for Regional Development" (FEDER). We would like to thank also the National Research Agency for supporting this research through the ANR TransBatiBois project (ANR-07-PBAT-008).

\section{REFERENCES}

Asan, H. 1998. Effects of wall's insulation thickness and position on time lag and decrement factor. Energy and Buildings 28:299-305.

Asan, H. 2006. Numerical computation of time lags and decrement factors for different building materials. Building and Environment 41:615-620.

Hameury, S. 2005. Moisture buffering capacity of heavy timber structures directly exposed to an indoor climate: a numerical study. Building and Environment 40:1400-1412.

ISO. International Standard Organisation. 1996. Thermal insulation - Determination of steadystate thermal transmission properties. ISO 8990. Calibrated and guarded hot box.

James, C.; Simonson, C. J.; Talukdar, P.; Roels, S. 2010. Numerical and experimental data set for benchmarking hygroscopic buffering models. International Journal of Heat and Mass Transfer 53:3638-3654. 
Kontoleon, K.J.; Bikas, D. K. 2007. The effect of south wall's outdoor absorption coefficient on time lag, decrement factor and temperature variations. Energy and Buildings 39(9): 1011- 1018.

Kunzel, H.M.; Holm, A.; Sedlbauer, K.; Antretter, F.; Ellinger, M. 2004. Moisture buffering effect of interior linings made from wood or wood based products. Fraunhofer Institute of Building Physics (IBP), Holzkirchen - Germany. IBP Report HTB-04/2004/e. 48 pp.

Mendes, N.; Winkelmann, F. C.; Lamberts, R.; Philippi, P. C. 2003. Moisture effects on conduction loads. Energy and Buildings 35(7):631-644.

Osanyintola, O.F.; Talukdar, P.; Simonson, C.J. 2006. Effect of initial conditions, boundary conditions and thickness on the moisture buffering capacity of spruce plywood. Energy and Buildings 38:1283-1292.

Osanyintola, O.F.; Simonson, C.J. 2006. Moisture buffering capacity of hygroscopic building materials: Experimental facilities and energy impact. Energy and Buildings 38:1270-1282.

Simonson, C.J.; Salonvaara, M.; Ojanen, T. 2004. Moderating Indoor Conditions with Hygroscopic Building Materials and Outdoor Ventilation. ASHRAE Transactions - USA. 110(2): 804-819.

Talukdar, P.; Osanyintola, O.F.; Olutimayin, S.O.; Simonson, C.J. 2007. An experimental data set for benchmarking 1-D, transient heat and moisture transfer models of hygroscopic building materials. Part II : Experimental, numerical and analytical data. International Journal of Heat and Mass Transfer 50:4916-4926. 
